\title{
Revista ADSO
}

ASSOCIAÇÃO DOS DOCENTES E ORIENTADORES DE MEDICINA GERAL E FAMILIAR

Ensino de Medicina Geral e Familiar no Curso de Mestrado Integrado em Medicina da Universidade da Beira Interior

A educação médica é um processo organizado que leva à aquisição de conhecimentos, atitudes e aptidões para atingir a proficiência.

Depressão: Um Problema por Resolver? A depressão é uma síndrome clínica comum, de causa multifactorial, com elevada prevalência e responsável por morbilidade importante e custos sociais crescentes. Estima-se que uma em cada cinco pessoas desenvolva depressão ao longo da vida.

Uso da Gabapentina na Melhoria Sintomática da Síndrome do Túnel Cárpico: Qual a Evidência? O Síndrome do Túnel Cárpico tem origem na compressão do nervo mediano do punho, causando parestesias, adormecimento e dor na mão. O tratamento da STC consiste na descompressão cirúrgica do nervo ou no tratamento conservador, nomeadamente com recurso à gabapentina.

\section{Voluntariado no Panamá}

Foi no mês de Maio de 2018, que tivemos a nossa primeira experiência de voluntariado médico além-fronteiras. Como internas do $4^{\circ}$ ano de MGF, optámos realizar um estágio de voluntariado, durante duas semanas, no Panamá, mais precisamente em Bocas del Toro.

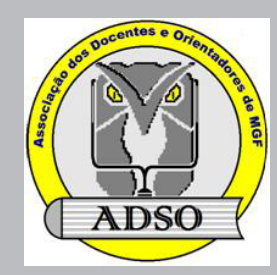





\section{Normas Editoriais}

A Revista da ADSO (RevADSO) reflete, em particular, o trabalho desempenhado pelos membros da ADSO na sua ação dedicada ao ensino e à prática da Medicina Geral e Familiar (MGF), quer na formação pré como na pós-graduada, particularmente nos âmbitos das unidades curriculares e do internato médico de MGF. E reflete também o trabalho, a opinião e os resultados, em estudos e reflexões, daqueles que são alvo da formação, quer alunos, quer internos de especialidade.

A RevADSO terá ainda abertura a outras áreas do conhecimento, afins da MGF e que, com ela, se completam na prossecução do objetivo de prestar cuidados integrados a todos aqueles que se dirigem ao seu Médico de Família A colaboração científica das Escolas que, em Portugal, se dedicam ao ensino destas matérias é, também, um objetivo crucial deste projeto.

A RevADSO tem um Conselho Científico e Revisor. O Corpo Redatorial será o responsável pela primeira análise do manuscrito e verificação de conformidades à temática. Será igualmente responsável pela distribuição aos Revisores e pela igualmente indispensável função de ter as revisões a tempo.

A RevADSO, pretende a publicação de artigos nas áreas da investigação, revisão baseada na evidência, qualidade de formação e das diferentes áreas da formação.

Os artigos podem ser escritos por especialistas em MGF, por alunos de mestrado integrado e por internos da especialidade de MGF, desde que versando a área da Revista, bem como por profissionais de outras áreas que reflitam sobre o ensino. Artigos sobre experiências no ensino pré e pós graduado em MGF são bem-vindos. Os artigos originais podem já ter sido apresentados parcialmente.

O(s) autor(es) deverá(ão) declarar em anexo que aceita(m) as regras da RevADSO e que cedem direitos de autor.

Os artigos propostos (manuscritos) deverão vir dirigidos à secção pretendida e:

1. Ser redigidos em Português, Inglês, Francês ou Espanhol, em coluna única, a dois espaços, com letra de dimensão 11 e em ficheiro word. Aconselha-se a utilização dos formatos de letra Times New Roman ou Arial. As quatro margens devem ser de $2,5 \mathrm{~cm}$. Todas as páginas devem ser numeradas incluindo a página do título. Devem ser inseridas quebras de página entre cada secção do manuscrito. 0 número de autores deve ser restrito aos que verdadeiramente participaram na conceção, execução e escrita do manuscrito, devendo tal ser apresentado em peça separada. As palavras chave, em número mínimo de três e máximo de seis, devem estar de acordo com o MeSH (Medical Subject Heding) - http://www.nlm.nih.gov/mesh. 
2. As Referências Bibliográficas devem cumprir os seguintes aspetos:

- Número de autores: até 6 , devem todos ser referidos; 7 ou mais autores, apenas os três primeiros, seguidos de et al.; as referências devem ser numeradas por ordem de entrada no texto e mencionadas da seguinte forma:

- Artigo de revista - Ex: Kusel MMH, Klerk NH, Holt PG, et al. Role of respiratory virus in acute and lower respiratory tract ilness in the first year of life. Ped Infect Dis J 2006;25:680-6.

- Capítulo de livro - Ex: Cherry JD, Nieves DL. The Common Cold. In: Feigin RD, Cherry JD, Demmler-Harrison GJ, Kaplan SL. Feijin \& Cherry's Textbook of Pediatric Infectious Diseases, 6th ed. Philadelphia. Saunders Elsevier; 2009;138-46.

- Livro - Ex: Nelson JD, Bradley JS. Nelson's Pocket Book of Pediatric Antimicrobial Therapy. 14th ed. Philadelphia. Lippincott Williams \& Wilkins; 2000.

- Página Web - Ex: Gostin LO. Drug use and HIV/AIDS (JAMA HIV/AIDS web site). June 1, 1996. Available at: http://www.ama-assn.org/special/hiv/ethics. Accessed June 26; 2004.

- Comunicações em congressos/jornadas - Ex: Harrigan PR, Don W, Weber AE, et al. Mutated RT and protease. (Abstract I - 115). In: 38th Interscience Conference on Antimicrobial Agents and Chemotherapy, San Diego, California, September 24 to 27, 1998. Washington, DC: American Society for Microbiology; 1998.

- Abreviaturas de Revistas, consultar http://home.ncifcrf.gov/research/ bja/

3. Ter parecer de comissão de ética (se investigação com seres humanos) ou de conduta ética, bem como de Comissão Nacional de Proteção de Dados, quando aplicável. [Nota: trabalhos baseados em questionários respondidos em anonimato, sigilo e confidencialidade, trabalhos baseados em análise de dados clínicos sem identificação de pessoas ou casos e trabalhos de análise de dados informáticos ou outros e que apenas reflitam conjuntos organizados já existentes, estão isentos de tais formalidades. No entanto, o Corpo Redatorial reserva-se o direito de ponderar em função de cada caso concreto].

4. Ser acompanhados de declaração de conflito de interesses. 
5. Estar organizados da seguinte forma, por áreas:

Investigação: [em ensino pré ou pós-graduado, e em medicina geral e familiar ou cuidados de saúde primários]

Título, Resumo, Palavras-chave, Introdução, Métodos, Resultados, Discussão, agradecimentos e Referências Bibliográficas.

Revisão baseada na evidência:

Título, Resumo, Palavras-chave, Introdução, Métodos, Resultados, Conclusões, Agradecimentos e Referências Bibliográficas.

Qualidade de formação: [avaliação de qualidade ou em ciclo de garantia de qualidade, formativa ou clínica]

Título, Resumo, Palavras-chave, Introdução, Métodos, Resultados, Conclusões, Agradecimentos e Referências Bibliográficas.

Formação: [projetos ou experiências considerados importantes a nível pré ou pós-graduado, e também relatos de docência ou de formação]

Título, Resumo, Palavras-chave, Introdução, Métodos, Resultados, Conclusões, Agradecimentos e Referências Bibliográficas.

6. Não exceder as 3500 palavras, ter um máximo de 6 quadros ou gráficos e até 60 referências.

7. É aconselhável que os autores indiquem três frases simples que marquem os pontos salientes do seu trabalho.

8. Em ficheiro word separado deverão ser enviados o(s) nomes(s) dos autores, sua afiliação e grau académico bem como contactos do autor responsável.

Os artigos deverão ser submetidos à RevADSO (revistaadso@sapo.pt) em suporte digital estando os quadros e os gráficos inseridos no local em que o texto a eles se refere, nomeadamente na secção de resultados, podendo estar em português do novo acordo ortográfico. Serão também aceites trabalhos em inglês, francês e espanhol. É obrigatória a referência à área a que o manuscrito se candidata.

Após receção, os trabalhos serão numerados por categoria e distribuídos ao Corpo Redatorial que se encarregará de fazer o primeiro exame e de, após aprovação, os submeter a dois membros do Concelho Científico e Revisor. De tais revisões será dado conhecimento ao proponente, sendo as duas revisões enviadas em simultâneo. Será solicitado que o tempo entre receção e resposta de revisão não exceda os 30 dias.

Após as rondas necessárias, o artigo será então aprovado pelo corpo redatorial e colocado na plataforma de publicação. 


\section{Editores}

\section{Conselho Científico}

Sede da Redação:

Rua de Moçambique, 33 R/C Dto

Bairro Norton de Matos

3030-062 Coimbra

Diretora e Editora:

Denise Alexandra Cunha Velho, USF

Santiago de Leiria, ACeS Pinhal Litoral

Número de registo na ERC: 126604

Periodicidade: Diária

Design: Patrícia Gaspar
Denise Alexandra Cunha Velho, USF Santiago de Leiria, ACeS Pinhal Litoral

José Augusto Rodrigues Simões, ACeS Baixo Mondego; Faculdade Ciências da Saúde da Universidade da Beira Interior

Luís Amorim Alves, USF St. André de CanideIo, ACeS Grande Porto VII - Gaia; Escola de Medicina da Universidade do Minho

Filipe Jorge Sousa Carvalheiro, Departamento de Ciências Biomédicas e Medicina da Universidade do Algarve

Filipe Prazeres, USF Beira Ria, ACeS Baixo Vouga; Faculdade de Ciências da Saúde da Universidade da Beira Interior

Inês Rosendo, UCSP Fernão de Magalhães, ACeS Baixo Mondego; Faculdade de Medicina da Universidade de Coimbra

Joana Monteiro, USF Odisseia, ACeS Grande Porto III - Maia/Valongo; Faculdade de Medicina da Universidade do Porto

Pedro Augusto Simões, USF Pulsar, ACeS Baixo Mondego; Faculdade de Ciências da Saúde, Universidade da Beira Interior

Pedro Fonte, USF do Minho, ACeS Cávado I - Braga; Escola de Medicina/Instituto de Investigação em Ciências da Vida e Saúde, Universidade do Minho

Prof. José Augusto Rodrigues Simões, ACeS Baixo Mondego; Faculdade Ciências da Saúde da Universidade da Beira Interior

Prof. Hernâni Pombas Caniço, Faculdade de Medicina da Universidade de Coimbra

Prof. Paulo Santos, Faculdade de Medicina da Universidade do Porto

Dr. Fernando Ferreira, ACES do Cávado III Barcelos/Esposende, Portugal

Prof. Luiz Miguel Santiago, USF Topázio, ACeS Baixo Mondego; Faculdade de Ciências da Saúde da Universidade da Beira Interior; Escola Superior de Tecnologias daSaúde de Coimbra, Portugal

\section{Estatuto Editorial}

A Revista ADSO é o órgão oficial de informação da Associação de Docentes e Orientadores de Medicina Geral e Familiar que foi criada em 2013 com o propósito de oferecer conteúdos rigorosos sobre a actividade profissional e científica relacionada com a Medicina Geral e Familiar em Portugal, focando-se no relato das experiências formativas desenvolvidas.

A Revista ADSO é constituída por um Corpo Editorial constituído pelo Diretor da Revista e Editores de Secção em exercício, salvo deliberação em contrário e assume-se como independente dos poderes políticos e económicos, bem como de qualquer credo, de qualquer doutrina ou ideologia, respeitando todas as opiniões ou crenças, assumindo o direito de emitir opinião própria, sempre no respeito integral pela Lei em vigor.

Prof. Isabel Pereira dos Santos, USF Conde de Oeiras, Aces Lisboa Ocidental e Oeiras; Faculdade de Ciências Médicas - Universidade Nova de Lisboa

Prof. Jaime Correia de Sousa, USF Horizonte, ULS Matosinhos; Escola de Ciências da Saúde da Universidade do Minho
A Revista ADSO respeita os direitos, liberdades e garantias consignadas na Constituição da República, cumpre a Lei de Imprensa e orienta-se pelo cumprimento dos princípios e orientações definidos neste Estatuto Editorial e pela sua Direção. 


\section{Índice}

08.

\section{Editorial}

Ensino de Medicina Geral e Familiar no Curso de Mestrado

Integrado em Medicina da Universidade da Beira Interior

14.

Editorial da Direção

16.

Investigação

Depressão: Um Problema por Resolver?

Sara Correia, Miguel Santos, Dilermando Sobral

23.

Revisão Baseada na Evidência

Uso da Gabapentina na Melhoria Sintomática da

Síndrome do Túnel Cárpico: Qual a Evidência?

Cristina Mesquita Neves, Adriana Vasconcelos, Marina Carneiro,

Marta Fevereiro

29.

Relato de Prática

Voluntariado no Panamá

Rita Ferreira, Ana Portela, Renata Almeida 


\title{
Editorial
}

\section{Ensino de Medicina Geral e Familiar no Curso de Mestrado Integrado em Medicina da Universidade da Beira Interior.}

\author{
José Augusto Simões \\ Professor Associado Convidado \\ Universidade da Beira Interior, Faculdade de Ciências da Saúde \\ http://orcid.org/0000-0003-2264-7086 \\ jars@fcsaude.ubi.pt \\ Filipe Prazeres \\ Professor Auxiliar Convidado \\ Universidade da Beira Interior, Faculdade de Ciências da Saúde \\ http://orcid.org/0000-0002-2849-5194 \\ filipeprazeresmd@gmail.com \\ Luiz Miguel Santiago \\ Professor Associado com Agregação \\ Universidade de Coimbra, Faculdade de Medicina \\ Ex-Regente de CSP da FCS-UBI \\ http://orcid.org/0000-0002-9343-2827 \\ Imsantiago@netcabo.pt \\ Miguel Castelo-Branco \\ Professor Associado com Agregação \\ Universidade da Beira Interior, Faculdade de Ciências da Saúde \\ Presidente da Faculdade de Ciências da Saúde e Diretor do Curso de Mestrado \\ Integrado em Medicina \\ https://orcid.org/0000-0002-6191-5912 \\ mcbranco@fcsaude.ubi.pt
}

A educação médica é um processo organizado que leva à aquisição de conhecimentos, atitudes e aptidões para atingir a proficiência. É um processo contínuo e dinâmico em que o atingir de cada objetivo abre a perspetiva de novos objetivos, permitindo estruturar estratégias mais eficientes para a execução de tarefas. No ensino médico, este processo estrutura-se através de um ciclo pré-clínico de estudos em ciências básicas, seguido de um ciclo clínico de formação médica. No fim, o processo de graduação é concluído e a Universidade reconhece a competência para a prática da medicina ${ }^{1}$.

O ensino de Medicina Geral e Familiar (MGF) na Faculdade de Ciências da Saúde da Universidade da Beira Interior remonta ao início do curso de Medicina nesta Universidade em $2001^{2}$. 
A MGF está incluída na área científica de Saúde Comunitária, no âmbito dos Cuidados de Saúde Primários (CSP), que foram distribuídos por três unidades curriculares (UC): no segundo (CSP I), quarto (CSP II) e quinto (CSP III) anos com 10 ECTS cada uma ${ }^{3}$. Existem ainda três outros momentos de contacto com os CSP. No primeiro ano o estágio observacional em Centro de Saúde de uma semana. No terceiro ano, a iniciar no próximo ano letivo, um estágio pré-clínico de MGF de uma semana e no sexto ano o estágio profissionalizante de quatro semanas em MGF (CSP IV).

Os objetivos pedagógicos de CSP / MGF pretendem que os alunos adquiram o conhecimento, as aptidões e as atitudes necessárias para lidar com as questões de saúde predominantes no âmbito da prática clínica de MGF e do contexto de uma prática centrada no paciente.

Todos os tutores das diferentes UC de CSP são Médicos de Família com a especialidade de MGF e com vínculo laboral à Universidade da Beira Interior, no quadro de acumulação parcial de funções públicas.

A lecionação de MGF, com a exceção do segundo ano, procura decorrer no cenário clínico de unidades funcionais de cuidados de saúde primários e de uma prática médica de acordo com a definição europeia de Medicina Geral e Familiar da WONCA ${ }^{4,5}$ (figura 1).

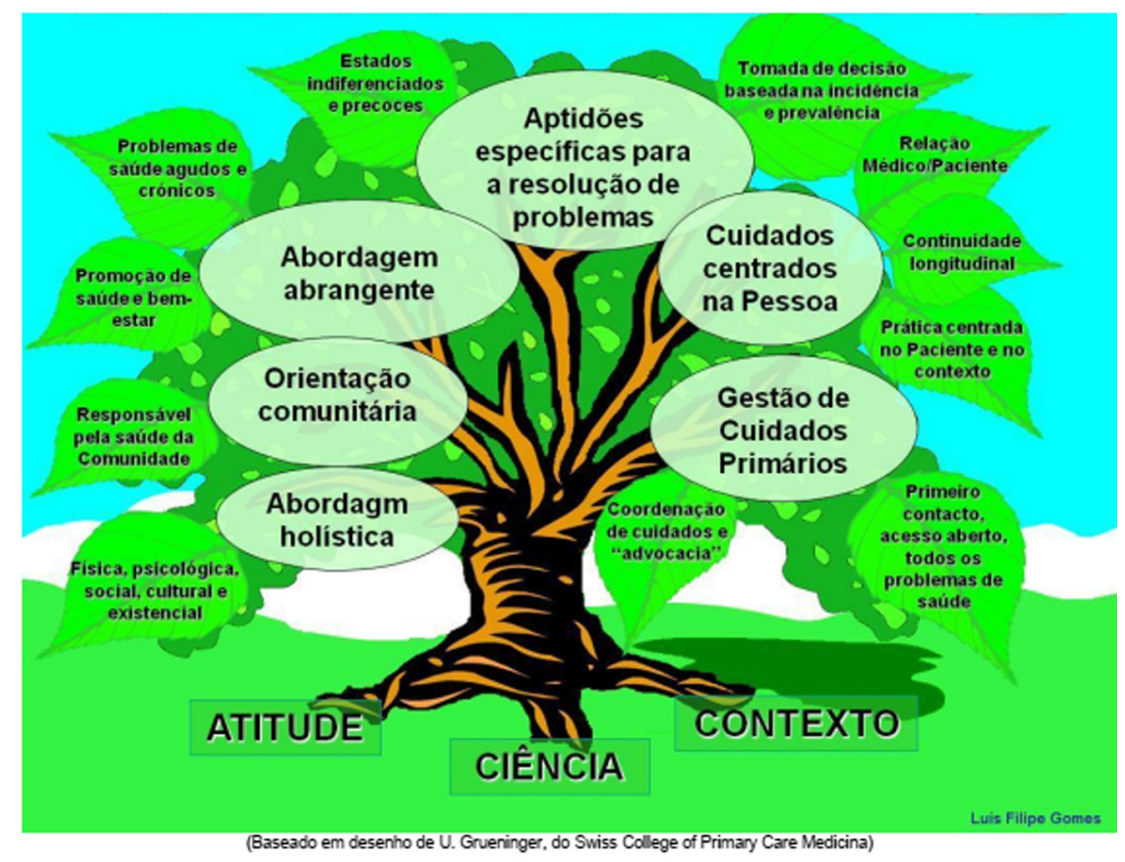

Figura 1. Definição europeia de Medicina Familiar. WONCA 
0 ensino pré-clínico é feito em pequenos grupos de tutoria e os estágios clínicos procuram a relação de 1-2 alunos por tutor. Todos os momentos formativos são sujeitos a avaliação. Pretende-se assim, ensinar Medicina Geral e Familiar (MGF) seguindo os melhores princípios, em termos de dinâmica, interatividade, prática, contexto e ciência.

São objetivos das três Unidades Curriculares (UC) de Cuidados de Saúde Primários (CSP):

- CSP I - O básico dos Cuidados de Saúde Primários e o contexto familiar - ( $2^{\circ}$ ano):

- Caracterizar a equipa de CSP;

- Entender como as unidades funcionais de CSP prosseguem a sua visão geral e familiar;

- Entender como os CSP se organizam e relacionam com a medicina hospitalar e com outros contextos de prática da Medicina;

- Conhecer a importância da promoção e desenvolvimento dos Programas Nacionais de Saúde;

- Conhecer a importância da família dos pacientes na relação saúde/ doença.

- $\operatorname{CSP} \|$ ( $4^{\circ}$ ano):

- Promover que os alunos adquiram o conhecimento, as aptidões e as atitudes necessárias para enfrentar os problemas de saúde mais prevalentes no âmbito da MGF e do seu contexto de prática clínica;

- Promover que os alunos contactem com os conceitos de Medicina Centrada na Pessoa, Empatia Médica e Capacitação da Pessoa.

- Promover que os alunos adquiram boas aptidões de comunicação;

- Promover que os alunos façam anotações e registos clínicos adequados;

- Promover que os alunos realizem uma consulta centrada na pessoa e de acordo com o modelo SOAP ${ }^{7,8}$.

- $\operatorname{CSP}$ III (5 ano):

- Adquirir conhecimentos, aptidões e atitudes necessárias para abranger os problemas de saúde mais comuns na prática da MGF;

- Adquirir conhecimentos, aptidões e atitudes éticas, de medicina centrada na pessoa, empatia e capacitação da pessoa;

- Adquirir conhecimentos e competências para atuar nos diferentes níveis de Prevenção em Medicina;

- Adquirir conhecimentos e competências para classificar de acordo com a ICPC-2;

- Adquirir conhecimentos, aptidões e atitudes necessárias para a gestão da Multimorbidade e da Polifarmacoterapia. 
- CSP IV - que não sendo unidade curricular autónoma (porque na logica de residências de "Prática Clínica" não existem, mas funciona como bloco autónomo - (6 ano):

- Adquirir conhecimentos, aptidões e atitudes necessárias para a realização e gestão de uma consulta.

- Desenvolver competências clínicas sendo capaz de identificar as necessidades de cuidados do doente, da família e da comunidade e planear e gerir as atividades e intervenções daí decorrentes e de monitorizar a sua evolução.

- Desenvolver a capacidade de trabalhar em cooperação com os outros profissionais que integram as equipes de saúde.

- Consolidar o reconhecimento do papel do médico de família como nuclear dentro do serviço nacional de saúde e aperfeiçoar o processo de centralidade na pessoa.

Com as diferentes UC de CSP pretende-se que os alunos terminem o curso de Medicina com conhecimentos e competências para:

- Abordagem interessada e holística das pessoas que recorrem aos serviços de saúde.

- Compreensão da dimensão do papel do médico de família e da abordagem necessária à resolução dos problemas relacionados com a medicina familiar, o que inclui:

- Capacidade em lidar com a ambiguidade;

- Utilização de dados estatísticos na tomada de decisões;

- Utilização da intuição na tomada de decisões;

- Recolha e registo de dados e informação;

- Compreensão dos marcadores e fatores de risco;

- Compreensão da função da família e problemas associados;

- Gestão do tempo no diagnóstico e tratamento da doença;

- Compreender a abordagem centrada na pessoa.

- Compreensão de:

- Morbilidade da comunidade;

- Apresentação de problemas;

- Padrões de sintomas e queixas;

- Medicamentos e tratamentos frequentemente utilizados;

- Multimorbilidade e polifarmacoterapia;

- Adequar ao contexto dos Cuidados de Saúde Primários Portugueses;

- Importância do trabalho em equipa e da aprendizagem contínua ao longo da vida;

- Abordagem crítica como método de crescimento profissional e melhoria na qualidade de prestação de serviços. 


\section{Como se operacionaliza este programa?}

CSP I: 100 horas de tutoria (36 horas) e estudo orientado: Fundamentos básicos, observação e perceção do que foi ensinado na tutoria;

CSP II: 112 horas de tutoria e prática com tutor em gabinete médico (64 horas): método WEED - SOAP aprendido, aplicado e avaliado (por tutor e consulente $)^{7,8}$;

CSP III: 120 horas de tutoria e prática com tutor em gabinete médico (64 horas): desenvolvimento de consulta e observação do ambiente dos Cuidados de Saúde Primários;

CSP IV: 100 horas de prática com tutor em gabinete médico: desenvolvimento de consulta e de prática clínica diária.

\section{Como se faz a avaliação dos alunos?}

CSP I: teste de escolha múltipla no fim de cada unidade pedagógica, três no total, e um teste integrado de todo o conteúdo da UC e uma estação OSCE, na avaliação básica integrada no final do ano letivo. Avaliação qualitativa de comportamentos e atitudes no decorrer da UC. Os alunos que não atingem os objetivos propostos são avaliados em exame final de todo o conteúdo de CSP I;

CSP II: teste de escolha múltipla no fim da rotação, realização de uma consulta segundo a metodologia SOAP (com avaliação pelo tutor através de lista de verificação, e pelo consulente), avaliação de trabalho observacional sobre tema proposto no início do ano letivo e realização de duas estações OSCE, na avaliação clínica integrada no final do ano letivo. Avaliação qualitativa de comportamentos e atitudes no decorrer da UC. Os alunos que não atingem os objetivos propostos são avaliados em exame final de todo o conteúdo de CSP II;

CSP III: teste de escolha múltipla no fim da rotação, realização de uma consulta (com avaliação pelo tutor através de lista de verificação, e pelo consulente), avaliação de trabalho observacional sobre tema proposto no início do ano letivo e realização de duas estações OSCE, na avaliação clínica integrada no final do ano letivo. Avaliação qualitativa de comportamentos e atitudes no decorrer da UC. Os alunos que não atingem os objetivos propostos são avaliados em exame final de todo o conteúdo de CSP III.

CSP IV: Avaliação qualitativa de comportamentos e atitudes no decorrer do estágio. 


\section{Referências Bibliográficas}

1. Santos $P$, Alves L, Simões JA. What distinguishes a competent doctor in medical education? Int J Med Educ. 2017; 8:270-272. Doi: 10.5116/ijme.595f.b2ad.

2. Universidade da Beira Interior. UBI em números 2003/2008; pág.6. Disponível em https://www.ubi.pt/Ficheiros/PDF/Conteudos/ubi_em_numeros_03_08.pdf.

3. Universidade da Beira Interior. Plano de Estudos Medicina. 2018. Disponível em https://www.ubi.pt/PlanoDeEstudos/52/1595/2018.

4. WONCA Europa. A definição europeia de Medicina Geral e Familiar (Clínica Geral/ Medicina Familiar). 2002. Disponível em http://www.woncaeurope.org/sites/default/files/documents/European\%20Definition\%20in\%20Portuguese.pdf.

5. European Academy of Teachers in General Practice. A definição europeia de Medicina Geral e Familiar (Clínica Geral/Medicina Familiar). Versão Reduzida. EURACT 2005. Rev Port Clin Geral. 2005; 21:511-6.

6. European Academy of Teachers in General Practice. A definição europeia de Medicina Geral e Familiar (Clínica Geral/Medicina Familiar). Versão Reduzida. EURACT 2005. Disponível em http://www.apmgf.pt/ficheiros/Definicao_MGFEURACT_2005.pdf.

7. Santiago LM, Neto I. SOAP Methodology in General Practice/Family Medicine Teaching in Practical Context. Acta Med Port. 2016 Dec; 29(12):854-859. Doi: 10.20344/amp.8405.

8. Santiago LM, Queirós V, Neto I, Castelo-Branco M, Barata LT. Lista de Verificação em Consulta para Estudantes de CSPII | 4 Ano no Ano Letivo 2012/2013 na Faculdade de Ciências da Saúde da Universidade da Beira Interior. Rev ADSO. 2013; 2: 23-28. 


\title{
Editorial da Direção
}

\author{
Renovação da equipa editorial da Revista ADSO \\ Denise Alexandra, USF Santiago de Leiria, ACeS Pinhal Litoral
}

Este ano tive a honra de aceitar o desafio de substituir o Prof. Luís Alves, na direcção da Revista ADSO, a quem agradeço, desde já, o trabalho que desenvolveu e por ter aceitado manter-se na equipa editorial. Agradeço também aos nossos leitores a paciência que têm demonstrado neste período de transição. Quis escrever este texto para partilhar convosco a nova equipa e o que desejo para o futuro da revista mas, antes, julgo ser interessante contar-vos um pouco da história da revista, à guiza de homenagem aos seus anteriores directores.

A Revista ADSO nasceu em 2013 como reflexo do trabalho desempenhado pela ADSO (Associação dos Docentes e Orientadores de MGF), na sua acção dedicada ao ensino e à prática da nossa especialidade, quer na formação pré como na pós-graduada. 0 seu primeiro editor foi o Professor Luiz Miguel Santiago, a quem se deve o início da revista e a sua publicação em 2013 e 2014. Seguiu-se o período de direcção pelo Professor Luís Alves, de 2015 a 2017, que conseguiu a legalização da revista junto da Entidade Reguladora da Comunicação Social e a obtenção do ISSN, assim como o site e a plataforma editorial para a revista online. Criou uma equipa editorial e implementou uma metodologia de revisão por pares.

Dando continuidade ao trabalho já desenvolvido, a equipa editorial foi reforçada com novos elementos. Queremos, desta forma, apresentar a nossa equipa e convidar-vos a partilharem connosco as vossas experiências e opiniões, especialmente no âmbito da formação. Este será o nosso principal foco. Todos os contributos serão bem-vindos, desde alunos, internos do ano comum, internos da formação específica, especialistas e todos os tipos de docente (tutores, formadores, assistentes e orientadores). Os nossos próximos desafios serão a agilização da publicação dos artigos online, assim que terminem o processo de revisão, e a implementação do DOI.

Apresento-vos a nova equipa editorial:

Denise Alexandra Cunha Velho, USF Santiago de Leiria, ACeS Pinhal Litoral - Directora

José Augusto Rodrigues Simões, ACeS Baixo Mondego; Faculdade Ciências da Saúde da Universidade da Beira Interior

Luís Amorim Alves, USF St. André de Canidelo, ACeS Grande Porto VII Gaia; Escola de Medicina da Universidade do Minho 
Filipe Jorge Sousa Carvalheiro, Departamento de Ciências Biomédicas e Medicina da Universidade do Algarve

Filipe Prazeres, USF Beira Ria, ACeS Baixo Vouga; Faculdade de Ciências da Saúde da Universidade da Beira Interior

Inês Rosendo, UCSP Fernão de Magalhães, ACeS Baixo Mondego; Faculdade de Medicina da Universidade de Coimbra

Joana Monteiro, USF Odisseia, ACeS Grande Porto III - Maia/Valongo; Faculdade de Medicina da Universidade do Porto

Pedro Augusto Simões, USF Pulsar, ACeS Baixo Mondego; Faculdade de Ciências da Saúde, Universidade da Beira Interior

Pedro Fonte, USF do Minho, ACeS Cávado I - Braga; Escola de Medicina/ Instituto de Investigação em Ciências da Vida e Saúde, Universidade do Minho

Aguardamos pelos vossos textos!

Denise Alexandra

Directora da Revista ADSO 


\section{Depressão: Um Problema por Resolver?}

\section{Depression: An Unsolved Problem?}

Sara Correia*, Miguel Santos*, Dilermando Sobral*

\section{Resumo}

Introdução: A depressão, síndrome multifactorial, apresenta prevalência, morbilidade e custos crescentes. Os estudos epidemiológicos sobre prevalência de perturbações mentais são escassos, tornando necessário estudos adicionais.

Objectivos: Avaliar a incidência e prevalência da depressão nos utentes da Unidade de Saúde Familiar de Ramalde (USFR), a relação entre depressão e factores demográficos e o seguimento e terapêutica farmacológica.

Métodos: Estudo observacional, transversal, retrospectivo. População: utentes com 18 ou mais anos inscritos na USFR. Amostra: utentes com diagnóstico de Perturbação Depressiva na lista de problemas activos do processo clínico. Variáveis: género, idade, anos de diagnóstico, data da última consulta, data e local da última prescrição, terapêutica farmacológica, grupo terapêutico. Instrumentos de recolha de dados: MIM@UF ${ }^{\circledR}$, SClínico $^{\circledR}$ e PEM $^{\circledR}$.

Resultados: A amostra foi de 1475 utentes (78\% mulheres). A maioria (60\%) tinha entre 40 e 69 anos. A taxa de incidência, no ano de 2014, foi de $2 \%$ e a prevalência, do total de utentes inscritos na USFR com mais de 18 anos $(n=12067)$, de $12 \%$, superior à do Agrupamento de Centros de Saúde Porto Ocidental, região norte e a nível nacional. A prevalência ajustada por género foi de $16,3 \%$ nas mulheres e de $6 \%$ nos homens e por escalões etários de 6,3\% entre os 18 e 39 anos e de $15 \%$ na faixa superior a 65 anos. A maioria teve consulta no último ano (88\%) e encontrava-se medicada com antidepressivos (82\%). A última prescrição ocorreu há mais de 6 meses em mais de metade dos casos. Os fármacos mais prescritos foram os inibidores selectivos de

\begin{abstract}
Introduction: Depression, a multifactorial syndrome, presents rising prevalence, morbidity and costs. Epidemiological studies about mental disorders prevalence are scarce, particularly in Portugal, precluding a solid assessment of this problem.
\end{abstract}

Objectives: To assess the incidence and prevalence of depression among Family Health Unit of Ramalde (FHUR) users, the relationship between depression and demographic factors, and the follow-up and drug therapy adopted by Family Physicians (FP).

Methods: Observational, cross-sectional, retrospective study. Population: users with 18 or more years old enrolled in FHUR. Sample: users diagnosed with Depressive Disorder registered in active problems' list on medical records. Variables: gender, age, year of diagnosis, date of last medical visit, date and place of last prescription, drug therapy, therapeutic group. Data collection instruments: MIM@UF ${ }^{\circledR}$, SClínico $^{\circledR}$ and PEM ${ }^{\circledR}$.

Results: Sample was composed by 1475 users (78\% women). The majority (60\%) were between 40 and 69 years old. Incidence, for the year 2014, was $2 \%$, and prevalence $12 \%$ of the patients 18 or more years old, higher than the known prevalence of Health Centers Grouping of Porto Ocidental, northern region and all country. Gender adjusted prevalence was $16.3 \%$ in women and $6 \%$ in men, and age adjusted prevalence was $6,3 \%$ in persons between 18 and 39 years old and $15 \%$, in people 65 years and older. Most subjects visited their FP in the past year (88\%) and were treated with antidepressant drugs (82\%). Time elapsed since last prescription was higher than 6 months in more than half of the cases. Most commonly prescribed drugs were selective 
recaptação da serotonina (SSRI) e 77\% das prescrições foram realizadas na USFR.

Discussão: A prevalência de depressão nesta população é alta, podendo dever-se a sobrediagnóstico. A diferença entre géneros é corroborada por outros estudos. Foi possível estabelecer populações de risco segundo a idade e género. Verificou-se que 12\% dos indivíduos diagnosticados com depressão não tinha tido consulta nos 12 meses anteriores. A maioria das prescrições correspondeu a SSRI, e foi efectuada nos Cuidados de Saúde Primários.

Palavras-chave: antidepressivos, cuidados de saúde primários, depressão, patologia depressiva.

\section{Introdução}

A depressão é uma síndrome clínica comum, de causa multifactorial, com elevada prevalência e responsável por morbilidade importante e custos sociais crescentes. Estima-se que uma em cada cinco pessoas desenvolva depressão ao longo da vida. ${ }^{1}$ Calcula-se que em 2020 os episódios de depressão major constituirão a segunda causa de anos de vida com saúde perdidos. ${ }^{2}$

Na maioria dos países, os Cuidados de Saúde Primários (CSP) são a porta de entrada para o acesso aos cuidados de saúde. Cerca de $50 \%$ das pessoas que sofrem de depressão acedem aos CSP, mas apenas numa pequena parte é feito o diagnóstico correcto e aplicada a terapêutica preconizada apesar dos tratamentos disponíveis serem efectivos e de fácil aplicabilidade. ${ }^{2}$

Em Portugal, as perturbações psiquiátricas afectam mais de um quinto da população. Deste valor global destacam-se as perturbações da ansiedade (16,5\%) e as perturbações depressivas (7,9\%). ${ }^{3}$ Um estudo recente a nivel dos CSP demonstrou que 7 a 12\% dos indivíduos apresentavam níveis "ligeiros" de stress, ansiedade e depressão, 11 a 17\% níveis "moderados", e 12 a $22 \%$ níveis "graves" ou "extremamente graves". 4

As mulheres têm maior risco de sofrer de depressão ${ }^{5-6}$, enquanto as faixas etárias mais elevadas apresentarão, segundo a literatura, menor probabilidade de sofrer de perturbações depressivas. $^{7}$

Os dados sobre o consumo de psicofármacos no nosso país evidenciam um padrão elevado de consumo, na população geral, nomeadamente de antidepressivos. Os estudos epidemiológicos de base populacional sobre serotonin reuptake inhibitors (SSRI) and $77 \%$ of prescriptions were made at Primary Care.

Discussion: Prevalence of depression in this population is high, which may be due to overdiagnosis. Differences between genders are corroborated by other studies. It was possible to determine age and gender related risk groups. About $12 \%$ of individuals were inadequately treated. Most prescriptions were SSRI, performed at Primary Care.

Key-words: antidepressant drugs, depression, depressive disorder, primary health care.

a prevalência de perturbações mentais são escassos, particularmente em Portugal ${ }^{7,8}$, pelo que são da maior importância estudos adicionais.

No âmbito destes dados e visando conhecer a realidade da Depressão na Unidade de Saúde Familiar de Ramalde (USFR), do Agrupamento de Centros de Saúde Porto Ocidental (ACeSPO), onde os investigadores exercem funções, foi desenvolvido este estudo, com os seguintes objectivos: avaliar a incidência e prevalência da depressão, analisar as diferenças entre géneros e os anos de diagnóstico, determinar os possiveis grupos populacionais com maior frequência de depressão (face às variáveis idade e género), avaliar o seguimento destes doentes (avaliação quantitativa - número de consultas), e qual a distribuição da terapêutica farmacológica adoptada.

\section{Métodos}

Trata-se de um estudo observacional, transversal e retrospectivo, cuja população era composta pelos 12067 utentes inscritos na USFR, com idade igual ou superior a 18 anos.

A prevalência (número total de casos) foi calculada com base no número de utentes com o diagnóstico de Perturbação Depressiva (P76) segundo a Classificação Internacional de Cuidados Primários - $2^{a}$ Edição (ICPC2) na lista de problemas activos do processo clínico electróniCo (SClínico $\left.{ }^{\circledR}\right)$, cumulativamente, à data de 31.12.2014. A taxa de incidência (número de novos casos), foi calculada para o ano de 2014, com base no número de novos diagnósticos registados na mesma codificação. 
As variáveis utilizadas neste estudo foram: género (variável dicotonómica - feminino/masculino), idade (variável contínua), anos de diagnóstico de depressão (variável contínua), data da última consulta registada na USFR, data da última prescrição, local da última prescrição (variável dicotonómica - USF/Externo), terapêutica antidepressiva (variável dicotonómica - sim/não), e grupo terapêutico utilizado (ADT - antidepressivos tricíclicos, AgoM - agonista melatoninérgico, NaSSA - noradrenérgicos e serotonérgicos específicos, NDRI - inibidores de recaptação de dopamina e noradrenalina, Outros tianeptina ou maprotilina, RIMA - inibidor reversível da MAO (monoaminooxidade), SARI - agonistas da serotonina e inibidores da sua recaptação, SNRI - inibidores da recaptação de serotonina e noradrenalina, ou SSRI - inibidores seletivos da recaptação de serotonina).

Os dados foram recolhidos pelos investigadores na USFR através da consulta do MIM@UF $^{\circledR}$ (Módulo de Informação e Monitorização das Unidades Funcionais), do SClínico ${ }^{\circledR}$ e da PEM ${ }^{\circledR}$ (Prescrição Eletrónica Médica), durante os meses de Abril e Maio de 2015, e posteriormente introduzidos e analisados numa base de dados informática, utilizando o software Statistical Package for the Social Sciences (SPSS ${ }^{\circledR}$, versão 20.0).

O SClínico ${ }^{\circledR}$ é o sistema informático desenvolvido pelos Serviços Partilhados do Ministério da Saúde (SPMS) para as instituições do Serviço Nacional de Saúde, com as funções de agenda e de processo clínico electrónico, permitindo o registo através do método de Weed. A $\mathrm{PEM}^{\circledR}$ é o módulo de prescrição electrónica igualmente desenvolvido pelos SPMS. O MIM@UF ${ }^{\circledR}$ é o módulo estatístico para exploração de dados a nível local, no contexto das unidades funcionais dos CSP.

\section{Resultados}

O total de utentes com idade igual ou superior a 18 anos com diagnóstico de Perturbação Depressiva na lista de problemas activos do processo clínico electrónico (SClínico $\left.{ }^{\circledR}\right)$, à data de 31.12.2014, era de 1475 utentes.

A prevalência de Perturbação Depressiva na USFR, calculada à data de 31.12.2014, era de $12 \%$, superior aos valores conhecidos relativos ao ACeSPO, a que a unidade pertence $(10,1 \%)$ (segundo dados do SIARS ${ }^{\circledR}$ 2014), à da zona norte do país (8,3\%) ou à que se verifica a nível nacional (7,9\%) (gráfico 1), de acordo com os valores da Direcão Geral de Saúde. ${ }^{7}$ No entanto, não é possível obter um significado estatístico sobre esta diferença, uma vez que não se conhecem os intervalos de confiança para as estimativas de prevalência apresentadas a nível nacional e regional.

Gráfico 1. Prevalência de depressão em Portugal, Região Norte, ACeSPO e USFR ${ }^{7}$

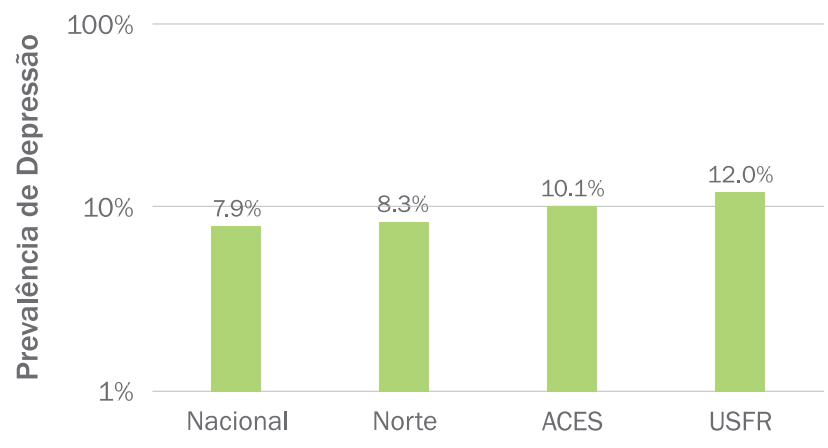

Da análise dos dados, conclui-se que a taxa de incidência em 2014 foi de 1,8\%, que corresponde aos 218 casos diagnosticados em 2014. Relativamente a este valor, pode-se afirmar que se tem mantido relativamente estável, atendendo ao número de casos diagnosticados nos 5 anos prévios à data do estudo, conforme evolução apresentada no gráfico 2.

Gráfico 2. Distribuição da amostra segundo anos de diagnóstico activo

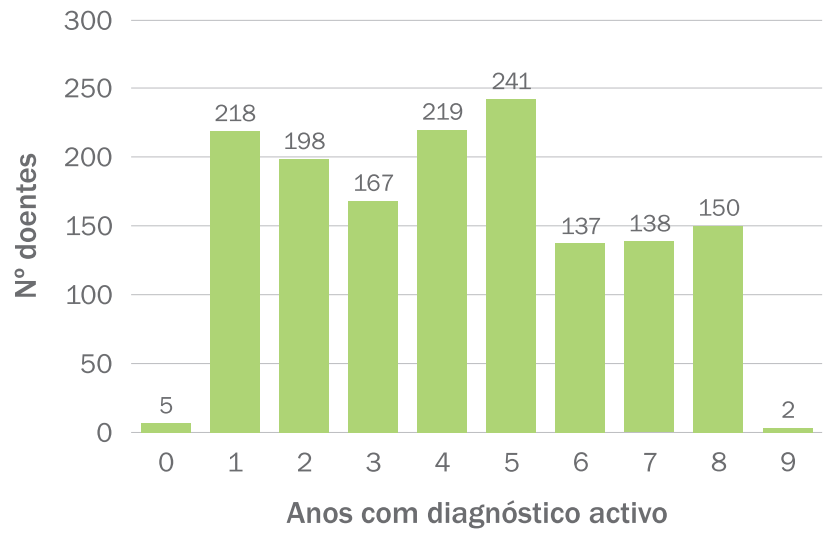

Neste estudo, 1150 utentes com codificação de Perturbação Depressiva eram do género feminino e 325 do masculino. É preciso notar que, para além de constituírem a maior fatia de utentes com este diagnóstico (78\%), as mulheres representam também a maioria (58,2\%) dos utentes com idade igual ou superior a 18 anos, motivo pelo qual foi efectuado o ajuste da prevalência por sexos. Após este ajuste, a proporção encontrada entre mulheres e homens na amostra deste estudo foi de 2,7 para 1 , com uma prevalência de depressão, na população total da USFR, de 16,3\% (1150/7034) nas mulheres e de $6 \%$ (325/5033) nos homens. 
Tal como para os géneros, também para a variável 'idade' os dados relativos à prevalência de Depressão foram ajustados (por faixa etária), por padronização directa, mediante a pirâmide etária da USFR. Assim, cerca de $60 \%$ dos utentes com diagnóstico de depressão têm idades compreendidas entre os 40 e os 69 anos (tabela 1).

Aproximadamente $70 \%$ dos indivíduos em estudo têm diagnóstico activo há menos de 5 anos $(n=1048)$. Cerca de 30\% apresentam diagnóstico activo há mais de 5 anos, alguns destes desde o início dos registos informáticos (n=457) (gráfico 2).

Tabela 1. Distribuição da amostra por género e idade

\begin{tabular}{cccc} 
Idade & Homem $n(\%)$ & Mulher $n(\%)$ & Total $n(\%)$ \\
\hline $\mathbf{2 0}$ & $2(26,0)$ & $11(74,0)$ & $13(0,9)$ \\
\hline $20-29$ & $17(25,0)$ & $51(75,0)$ & $68(4,6)$ \\
\hline $30-39$ & $43(21,9)$ & $153(78,1)$ & $196(13,3)$ \\
\hline $40-49$ & $67(22,1)$ & $236(77,9)$ & $303(20,5)$ \\
\hline $50-59$ & $64(21,3)$ & $236(78,7)$ & $300(20,3)$ \\
\hline $60-69$ & $62(22,8)$ & $210(77,2)$ & $272(18,5)$ \\
\hline $70-79$ & $41(22,4)$ & $142(77,6)$ & $183(12,4)$ \\
\hline $80-89$ & $25(21,4)$ & $92(78,6)$ & $117(7,9)$ \\
\hline$>90$ & $4(17,4)$ & $19(82,6)$ & $23(1,6)$ \\
\hline Total & $325(22,0)$ & $1150(78,0)$ & 1475
\end{tabular}

Uma grande maioria dos indivíduos diagnosticados (88\%) teve consulta presencial nos 12 meses prévios à data da recolha dos dados deste estudo; no entanto, uma percentagem não desprezivel (aproximadamente 12\%) não tinha consulta há mais de um ano.

Cerca de $82 \%$ dos utentes com diagnóstico de depressão activo estava ou já tinha sido medicado com terapêutica farmacológica antidepressiva, mas cerca de 18\% não tinham registo de qualquer prescrição com terapêutica farmacológica antidepressiva no registo clínico electrónico. A maior fatia das prescrições daqueles fármacos foi realizada a nível dos cuidados de saúde primários (USFR) - aproximadamente 77\% (tabela 2).

Tabela 2. Prescrição de terapêutica antidepressiva e local da última prescrição

\begin{tabular}{c|c|c|c}
\hline Prescrição & Homens $\mathrm{n}(\%)$ & Mulheres $\mathrm{n}(\%)$ & Total $\mathrm{n}(\%)$ \\
\hline Não & $80(29,7)$ & $179(69,1)$ & $259(17,6)$ \\
\hline Sim & $245(20,1)$ & $971(79,9)$ & $1216(82,4)$ \\
\hline & Local da última prescrição & \\
\hline USF & - & - & $939(77,2)$ \\
\hline Externo & - & - & $277(22,8)$ \\
\hline Total & & & 1216 \\
\hline
\end{tabular}

Dos indivíduos com registo de prescrição farmacológica prévia, 66\% foram medicados nos últimos 12 meses, enquanto para os restantes 34\% não foi objectivada na plataforma informática PEM qualquer prescrição de terapêutica antidepressiva no último ano.

Os fármacos antidepressivos mais utilizados pertenciam à classe dos inibidores selectivos da recaptação de serotonina (SSRI), seguindo-se os inibidores da recaptação de serotonina e noradrenalina (SNRI), noradrenérgicos e serotonérgicos específicos (NaSSA) e agonistas da serotonina e inibidores da sua recaptação (SARI) (gráfico 3).

Gráfico 3. Grupos terapêuticos utilizados

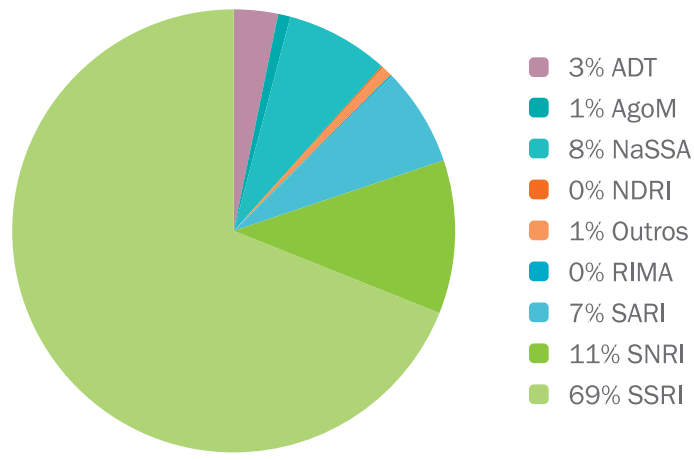

Legenda: ADT - antidepressivos tricíclicos, AgoM - agonista melatoninérgico, NaSSA - noradrenérgicos e serotonérgicos específicos, NDRI - inibidores de recaptação de dopamina e noradrenalina, Outros - tianeptina ou maprotilina, RIMA - inibidor reversível da MAO (monoaminooxidade), SARI - agonistas da serotonina e inibidores da sua recaptação, SNRI - inibidores da recaptação de serotonina e noradrenalina, SSRI - inibidores seletivos da recaptação de serotonina.

\section{Discussão}

Este estudo orientou-se para a avaliação da prevalência de depressão com base nas codificações do registo clínico electrónico (obtida retrospectivamente), pelo que não é possível avaliar se todos os casos correspondem a um diagnóstico correcto desta patologia, pois não se realizou nenhuma avaliação do diagnóstico clínico individual contrastado com outra forma de diagnóstico ou medição de perturbação depressiva. Existe uma possibilidade de sobrediagnóstico, por um conjunto de factores, entre os quais alguma sobrevalorização de parâmetros ou queixas do foro psíquico / somático; Do mesmo modo, neste estudo, não se procurou sistematicamente averiguar se eventuais casos de Depressão Major considerados em remissão parcial poderiam antes ser atribuídos a Perturbação Distímica. ${ }^{3,8}$ Outro dos possíveis factores de sobrediagnóstico é a falha em retirar o código de Depressão dos problemas activos do 
processo clínico, em situações em que terá havido cura clínica e, consequentemente, não existirem já os pressupostos para manutenção dessa classificação.

Não se pode, assim, excluir que devido aos condicionalismos do estudo, a amostra utilizada seja enviesada, o que explicaria uma prevalência de perturbação depressiva na USFR (12\%) mais elevada quando comparada com a prevalência relativa ao ACeSPO, à região norte ou a nível nacional. Alguns autores referem que existe uma tendência para subdiagnosticar a depressão, facto com implicações quanto às decisões terapêuticas. ${ }^{11}$

Comparativamente aos dados nacionais já publicados ${ }^{3,7}$ verifica-se que a prevalência de perturbação depressiva encontrada entre os utentes da USFR é superior em cerca de 50\% à verificada para a população portuguesa, nos estudos referidos, com os reparos manifestados atrás.

A maior prevalência de depressão no género feminino (proporção encontrada de 2,7:1) é um resultado esperado, dado esta perturbação ser mais frequente nas muIheres. A justificação passa por razões de ordem fisiopatológica descritas na literatura (embora não totalmente estabelecidas), podendo também referir-se como factores etiológicos/agravantes de depressão a exigência social imposta à mulher bem como o nível sociocultural. Apontam-se ainda outras causas, que podem enviesar os resultados obtidos, nomeadamente: maior procura de cuidados de saúde pelas mulheres, com ênfase para os CSP: encontra-se descrito no nosso país praticamente o dobro da taxa de utilização de cuidados de saúde pelas mulheres e maior tendência destas a comunicar espontaneamente queixas subjectivas de natureza psíquica. ${ }^{7,9}$

A proporção encontrada entre mulheres e homens na amostra deste estudo foi de 2,7 para 1 . Outros trabalhos referem proporções variáveis entre si, mas concordantes no que se refere à predominância do género feminino. ${ }^{10}$

Em Portugal, as estimativas da prevalência da depressão apontam para diferenças significativas de acordo com a idade, emergindo um padrão de maior expressão quantitativa nos escalões mais jovens, enquanto o escalão de indivíduos acima dos 65 anos apresenta prevalências estimadas significativamente mais baixas que nas restantes faixas etárias, aspecto que segundo os autores poderá estar eventualmente associado um componente de enviesamento de memória (memória selectiva) e comum subvalorização das queixas dos indivíduos idosos por partes dos clínicos. ${ }^{3,12}$
No presente estudo, verificou-se um aumento significativo da prevalência de patologia depressiva apenas após os 30 anos. Entre os 18 e os 30 anos, a prevalência foi de $10,7 \%$ e cerca de $60 \%$ dos utentes com diagnóstico de depressão tinham idades compreendidas entre os 40 e os 69 anos. A este facto poder-se-á associar a carência socioeconómica da população adulta e, sobretudo, idosa da área geográfica que a USFR serve e da sua estreita relação com uma maior debilidade cognitiva e psíquica com consequente susceptibilidade para a depressão. ${ }^{13}$

É também importante salientar que a prevalência da depressão encontrada nos indivíduos com mais de 65 anos foi de aproximadamente $22 \%$, um valor estatisticamente superior quando comparado a outros relatórios nacionais. Este valor poderá relacionar-se com o facto de a população estudada ter maior número de indivíduos naquela faixa etária comparativamente aos estudos citados. ${ }^{3,7}$ Neste âmbito, encontra-se bem documentada a susceptibilidade dos indivíduos idosos para psicopatologia, sendo mesmo aceite como grupo de risco no que se refere a perturbação depressiva. São, neste âmbito, apontadas como possíveis causas a deterioração física e cognitiva relacionadas com o factor idade, bem como a menor ocupação diária e o isolamento social. ${ }^{9}$

Quase um terço dos indivíduos em estudo apresentava diagnóstico activo há mais de 5 anos, muitos desde o início dos registos informáticos. A este facto os investigadores atribuem hipóteses causais explicando a duração prolongada da patologia tais como: parte daqueles diagnósticos ainda se manter, alguns casos corresponderem a recaídas, tratar-se de outras patologias depressivas descritas igualmente em vários trabalhos (integradas no mesmo código da ICPC-2) como distimia ou perturbação bipolar. Poderão ainda tratar-se de episódios já terminados, mas que o médico não transpôs para inactivos, ou meros erros de codificação.

Cerca de $12 \%$ dos utentes estudados não tinha consulta há mais de um ano, colocando-se em causa, nestes casos, o acompanhamento adequado dos indivíduos com depressão, muito embora se possam considerar vieses que justifiquem estes dados: possibilidade de diagnóstico incorrecto, erros de codificação, diagnósticos já não activos mas que não foram transpostos para inactivos, utentes com depressão que não compareceram a consulta quando convocados ou ausência de convocatória - parâmetros não avaliados pelos investigadores. 
Constitui ainda uma debilidade deste estudo o facto de em caso de consulta presencial há menos de 12 meses não ter sido verificado se o problema "depressão" foi abordado/codificado na mesma consulta, o que permitiria detectar problemas como a má qualidade de registos, não codificação ou a não abordagem do assunto durante o contacto médico-doente, não significando assim necessariamente o acompanhamento adequado da patologia em causa.

Aproximadamente $18 \%$ dos indivíduos com diagnóstico activo não estavam medicados com terapêutica antidepressiva. Este resultado poderá ser explicado pelo facto de os utentes deixarem de cumprir o tratamento farmacológico por vontade própria ou pela não abordagem do problema por parte dos clínicos nos diferentes contactos com os utentes (poder-se-á apontar esquecimento, má qualidade dos registos ou o tempo disponível para a consulta) condicionando, assim, a ausência de prescrição daquelas terapêuticas.

Para cerca de um terço dos indivíduos com prescrição prévia não foi observada qualquer prescrição de terapêutica antidepressiva nos 12 meses prévios à recoIha dos dados. Confrontando os resultados relativos ao "tempo decorrido desde a última consulta" a estes últimos, poder-se-á inferir que alguns dos utentes que não têm prescrição há mais de um ano poderão corresponder a alguns utentes que não tiveram consulta no mesmo período.

Poder-se-á, igualmente, retirar importantes conclusões quando observados os dados relativos ao local de prescrição dos psicofármacos. Como é conhecido, os CSP são a porta de acesso à saúde da grande maioria dos utentes do Serviço Nacional de Saúde (SNS), facto semelhante na maioria dos países. É, portanto, a nível primário que a larga maioria dos diagnósticos de depressão são hoje realizados e, neste contexto, é onde se efectua o seguimento médico dos utentes que sofrem desta patologia, salvo as devidas excepções merecedoras de referenciação para os Cuidados de Saúde Secundários. No presente estudo, cerca de $78 \%$ do total de prescrições medicamentosas foram realizadas na USFR, enquanto as restantes se dividiam entre o Hospital de referência em cuidados de Psiquiatria e de Saúde Mental da área geográfica da unidade de saúde e outras entidades privadas.

Realça-se, assim, o papel do Médico de Família que, pela sua privilegiada posição face ao utente e estreito contacto com os seus factores pessoais e ambientais, pode ser relevante na detecção adequada e atempada de psicopatologia, nomeadamente de perturbação depressiva.
Os fármacos antidepressivos mais utilizados pertenciam à classe dos SSRI. Segundo as mais recentes normas de orientação clínica, qualquer fármaco antidepressivo poderá ser utilizado no tratamento da depressão desde que a sua escolha tenha como base a sua tolerabilidade, segurança, menor custo, bem como a história individual do doente, as suas preferências e os antecedentes de resposta a tratamentos realizados anteriormente, não existindo diferenças significativas quanto à eficácia.

Dada a menor amplitude e gravidade de efeitos secundários, assim como a boa tolerabilidade e perfil de segurança cardiovascular mais favorável atribuídos aos SSRI, estes justificam assim a sua escolha em maior escala pela generalidade dos clínicos nos últimos anos, facto também observado neste estudo. ${ }^{12}$

Em conclusão, a falta de estudos epidemiológicos de base populacional sobre a prevalência de perturbações mentais está bem patente na escassa literatura existente, particularmente em Portugal. Assim, as consequências deste estudo poderão ser positivas se os resultados forem adequadamente enquadrados e entendidos.

Este estudo, cuja validade se baseia no tratamento de dados com satisfatória cobertura populacional, permitiu conhecer a taxa de prevalência de depressão entre os utentes da USFR, mais elevada que o esperado. Os autores encontraram ainda diferenças entre géneros, com as mulheres a apresentarem níveis mais elevados de depressão. Foi possível estabelecer populações de risco quanto à idade, com a existência de dois picos, entre a quinta e sexta década e nos indivíduos com mais de 65 anos.

Os resultados não dão todas as respostas e produzem novas questões, devendo ser vistos à luz dos seus limites. É de fundamental importância delinear estratégias futuras junto dos profissionais de saúde, de forma a clarificar sintomas e critérios de diagnóstico, com o objectivo de melhorar os cuidados à população e obter ganhos em saúde.

\section{Agradecimentos}

Os autores agradecem aos colegas Dra. Carla Silva, Dra. Iryna Mykolyshyn, Dra. Lígia Sousa e Dr. Pedro Sousa a colaboração no processo de colheita de dados. 


\section{Referências Bibliográficas}

1. World Health Organization. Mental health: facing the challenges, building solutions: report from the WHO European Ministerial Conference, 2005. Acesso a 23 Abril, 2016.

2. Gusmão, Xavier, Heitor, Bento, \& Almeida. Depressive disorder burden: global epidemiological issues and information needs in Portugal. Acta Med Port. 2005 MarApr;18(2):129-46

3. Almeida JMC, Xavier M. Estudo Epidemiológico Nacional de Saúde Mental - $1 .^{\circ}$ Relatório. 2013. Faculdade de Ciências Médicas, Universidade Nova de Lisboa.

4. Apóstolo J, Alves L, Figueiredo MH, et al. Depression, anxiety and stress in primary health care users. Revista Latino-Americana de Enfermagem; 2011; 19(2), 348-353.

5. Bebbington, P. E. The origins of sex differences in depressive disorder: bridging the gap. International Review of Psychiatry, 1996. 8, 295 -332.

6. Bebbington, P. E. Sex and depression. Psychological Medicine, 1998. 28, 1-8.

7. Direção-Geral da Saúde (Março.2016). Saúde Mental em Números 2015. Lisboa.

8. Gonçalves B, Fagulha T, Ferreira A. A depressão nas mulheres de meia idade: estudo sobre as utentes dos cuidados de saúde primários. Psicologia; 2005; 19(1-2), 39-56.

9. Resina T, Pinhão A, Neto L, et al. Depressão e ansiedade na consulta de clínica geral/ médico de família. Acta Méd. Port. 1989; 2(1):7-10.

10. World Health Organization. The world health report 2001 - Mental Health: new understanding, new hope. Geneva: World Health Organization; 2001.

11. Gonçalves B, Fagulha T, Prevalência e Diagnóstico da Depressão em Medicina Geral e Familiar, Rev. Port. Clín. Geral 2004; 20:13-27.

12. Direção-Geral de Saúde. Circular Normativa n . 034/2012 - Terapêutica Farmacológica da Depressão Major e da sua Recorrência no Adulto de 30/12/2012, disponível em https://www.dgs.pt/directrizes-da-dgs/normas-ecirculares-normativas/norma-n-0342012-de-30122012. aspx. Acesso a 1 Março, 2016.

13. InstitutoNacionaldeEstatísticaCensos2011. Disponívelem https://www.ine.pt/xportal/xmain?xpid=INE\&xpgid=ine_ bdc_tree\&contexto=bd\&selTab=tab2 (Acesso em 29 de Setembro de 2017)

\section{Conflito de Interesses}

Os autores declaram não ter conflitos de interesses. 


\title{
Uso da Gabapentina na Melhoria Sintomática da Síndrome do Túnel Cárpico: Qual a Evidência?
}

\author{
Cristina Mesquita Neves*, Adriana Vasconcelos*, Marina Carneiro*, Marta Fevereiro*
}

\section{Resumo}

Introdução: O Síndrome do Túnel Cárpico (STC) tem origem na compressão do nervo mediano do punho, causando parestesias, adormecimento e dor na mão. O tratamento da STC consiste na descompressão cirúrgica do nervo ou no tratamento conservador, nomeadamente com recurso à gabapentina.

Objetivos: O STC é, empiricamente, uma patologia muito prevalente nos cuidados de saúde primários e o médico de família depara-se com limitadas opções terapêuticas. Assim, o objetivo deste estudo é realizar uma revisão baseada na evidência acerca da eficácia do uso da gabapentina na melhoria sintomática da STC.

Métodos: Foi realizada uma pesquisa nas bases de dados Medline, Cochrane, National Guideline Clearinghouse, National Institute for Health and Care Excellence (NICE), British Medical Journal (BMJ), Database of Abstracts of Reviews of Effectiveness (DARE), Essential Evidence Plus (EEP), e principais fontes de dados portuguesas, de artigos publicados de janeiro de 2006 até novembro de 2016, utilizando as palavras-chave (termos MeSH): "gabapentin" e "carpal tunnel syndrome". Para avaliação dos níveis de evidência (NE) e atribuição de forças de recomendação (FR) foi utilizada a escala Strenght of Recommendation Taxonomy (SORT).

Resultados: Foram encontrados 37 artigos, dos quais 3 cumpriam os critérios de inclusão. 0 ensaio clínico aleatorizado (ECAC), de Hui A.C. et al., concluiu que a gabapentina não produziu redução significativa na severidade dos sintomas (NE 1). No entanto, outro ECAC e

\begin{abstract}
Introduction: The Carpal Tunnel Syndrome (CTS) originates in the compression of the median nerve of the wrist, causing paresthesia, numbness and pain in the hand. The treatment of CTS consists of surgical decompression of the nerve or conservative treatment, in particular using gabapentin.
\end{abstract}

Objectives: CTS is, empirically, a very prevalent pathology in primary health care and the family physician is faced with limited therapeutic options. Thus, the aim of this study is to conduct an evidence-based review of the efficacy of gabapentin in the symptomatic improvement of CTS.

Methods: A survey was conducted in the Medline, Cochrane, National Guideline Clearinghouse, National Institute for Health and Care Excellence (NICE), British Medical Journal (BMJ) Database of Abstracts of Reviews of Effectiveness (DARE), Essential Evidence Plus (EEP), and main sources of Portuguese data, from articles published from January 2006 to November 2016, using the keywords (MeSH terms): "gabapentin" and "carpal tunnel syndrome". The Strenght of Recommendation Taxonomy (SORT) scale was used to assess the evidence levels (EL) and assignment of strenght of recommendation (SR).

Results: They were found 37 articles, of which 3 fulfilled the inclusion criteria. The randomized controlled trial (RCT), by Hui A.C. et al., concluded that gabapentin did not produce a significant reduction in symptom severity (EL 1). However, another RCT and a prospective cohort

\footnotetext{
* USF do Mar, ACeS Póvoa de Varzim

As autoras tiveram igual contribuição para o artigo.
} 
um estudo de coorte prospetivo evidenciaram a eficácia da gabapentina na redução sintomática do STC, com NE 1 e NE 2, respetivamente.

Conclusões: Apesar da inclusão de dois ensaios clínicos de alta qualidade e NE 1, pelos achados inconsistentes entre os dois estudos e pela inclusão de uma coorte prospetiva com desenho de estudo com qualidade inferior, foi considerada não existir evidência da eficácia da gabapentina na melhoria sintomática da STC com FR B. Serão necessários mais estudos que clarifiquem a sua eficácia, mas também o esquema posológico mais adequado, efeitos adversos e benefícios a longo prazo.

Palavras-chave: gabapentina, Síndrome do Túnel Carpal

\section{Introdução}

A síndrome do túnel do cárpico (STC) é a síndrome compressiva nervosa periférica mais comum em todo o mundo. ${ }^{1}$ Esta é causada pela compressão do nervo mediano no punho, causando sintomas como parestesias, adormecimento e dor na mão, que pode irradiar para o antebraço e ombro. ${ }^{2}$ Em casos mais severos os músculos inervados pelo nervo mediano podem ser afetados e resultar na diminuição da força muscular da mão. ${ }^{1}$

A etiologia desta síndrome é ainda desconhecida, mas presume-se uma origem multifatorial. São conhecidos diversos fatores de risco como diabetes mellitus, menopausa, hipotiroidismo, obesidade, artrite e gravidez. ${ }^{1}$ A história clínica e exame objetivo permanecem como gold standard para o diagnóstico, existindo ainda bastante controvérsia acerca da necessidade de exames adicionais, como eletromiografia e ecografia, para apoiar a decisão do tratamento a efetuar. ${ }^{1}$

O tratamento do STC consiste na descompressão cirúrgica do nervo ou no tratamento conservador. Apesar de vários estudos mostrarem que o tratamento cirúrgico resulta num melhor alívio sintomático, ${ }^{2,4}$ uma meta-analise recente concluiu que a abordagem conservadora deve ser a primeira opção de tratamento do STC, reservando a abordagem cirúrgica no caso de falha da abordagem conservadora. ${ }^{3}$ Dentro das opções de tratamento conservador surgem fármacos (injeção local de corticoides, vitamina $\mathrm{B}$, diuréticos, anti-inflamatórios não esteroides e outros), laserterapia, utilização de ortóteses, terapia por ultrassons, alterações ergonómicas, fisioterapia e exercícios dirigidos. ${ }^{3}$ study evidenced the efficacy of gabapentin in reduction of CTS symptoms, with EL 1 and EL 2, respectively.

Conclusions: Despite the inclusion of two high quality and EL 1 clinical trials, the inconsistent findings between the both studies and the inclusion of a prospective cohort with lower quality study design, there was no evidence of the efficacy of gabapentin in the symptomatic improvement of CTS with SR B. Further studies will be needed to clarify its efficacy, but also the most appropriate dosing regimen, adverse effects and long-term benefits.

Keywords: gabapentin, Carpal Tunnel Syndrome

Neste contexto, alguns estudos apontam para a utilidade do uso da gabapentina no STC. ${ }^{5,6}$ A gabapentina é um medicamento antiepilético, mas é também utilizado para alívio da dor neuropática em diferentes patologias, com eficácia na neuropatia diabética, nevralgia pós-herpética e dor neuropática mista. ${ }^{7}$ Dada a componente neuropática dos sintomas do STC, é possível considerar a utilidade da gabapentina no tratamento dos casos leves a moderados do STC que são refratários a outros tratamentos conservadores ou quando a abordagem cirúrgica não é considerada. ${ }^{5}$

O STC é, empiricamente, uma patologia muito prevalente nos cuidados de saúde primários e o médico de família depara-se frequentemente com limitadas opções terapêuticas. Assim, o objetivo deste estudo é realizar uma revisão baseada na evidência acerca da eficácia do uso da gabapentina na melhoria sintomática da síndrome do túnel cárpico.

\section{Métodos}

Foi realizada uma pesquisa nas bases de dados $\mathrm{Me}$ dline, Cochrane, National Guideline Clearinghouse, National Institute for Health and Care Excellence (NICE), British Medical Journal (BMJ), Database of Abstracts of Reviews of Effectiveness (DARE), Essential Evidence Plus (EEP), e principais fontes de dados portuguesas. Foram selecionados Ensaios Clínicos (EC), MetaAnálises (MA), Revisões Sistemáticas (RS) e Normas de Orientação Clínica (NOC) publicados de janeiro de 2006 
até à data da pesquisa, em novembro de 2016. Foram admitidos na pesquisa os artigos que estivessem escritos em inglês, português e espanhol e foram utilizadas as seguintes palavras-chave (termos MeSH): "gabapentin" e "carpal tunnel syndrome".

Como critérios de inclusão consideraram-se os artigos cuja população fosse constituída por adultos $(\geq 18$ anos), com diagnóstico de Síndrome do Túnel Cárpico, e em que a intervenção fosse o uso de gabapentina comparativamente ao uso de placebo ou ausência de intervenção. 0 resultado medido foi melhoria sintomática, nomeadamente analgésica e funcional.

Foram usados como critérios de exclusão: artigos duplicados, ensaios clínicos incluídos em revisões sistemáticas, discordância com o objetivo da revisão e artigos em que a população incluísse grávidas ou pessoas previamente intervencionadas cirurgicamente para tratamento do STC.
Os artigos selecionados foram avaliados através da checklist de António Vaz Carneiro "Como avaliar a investigação clínica. O exemplo da avaliação crítica de um ensaio clínico.", tendo sido incluídos aqueles considerados de "boa qualidade". 8

Para avaliação dos níveis de evidência e atribuição de forças de recomendação foi utilizada a Escala Strength Of Recommendation Taxonomy (SORT) da American Academy of Family Physicians.

\section{Resultados}

Foram encontrados 37 artigos na pesquisa inicial, tendo sido selecionados 3 artigos (Figura 1): dois ensaios clínicos aleatorizados e controlados (ECAC) e um estudo de coorte prospetivo (Tabela 1).

Figura 1. Esquema de seleção dos artigos

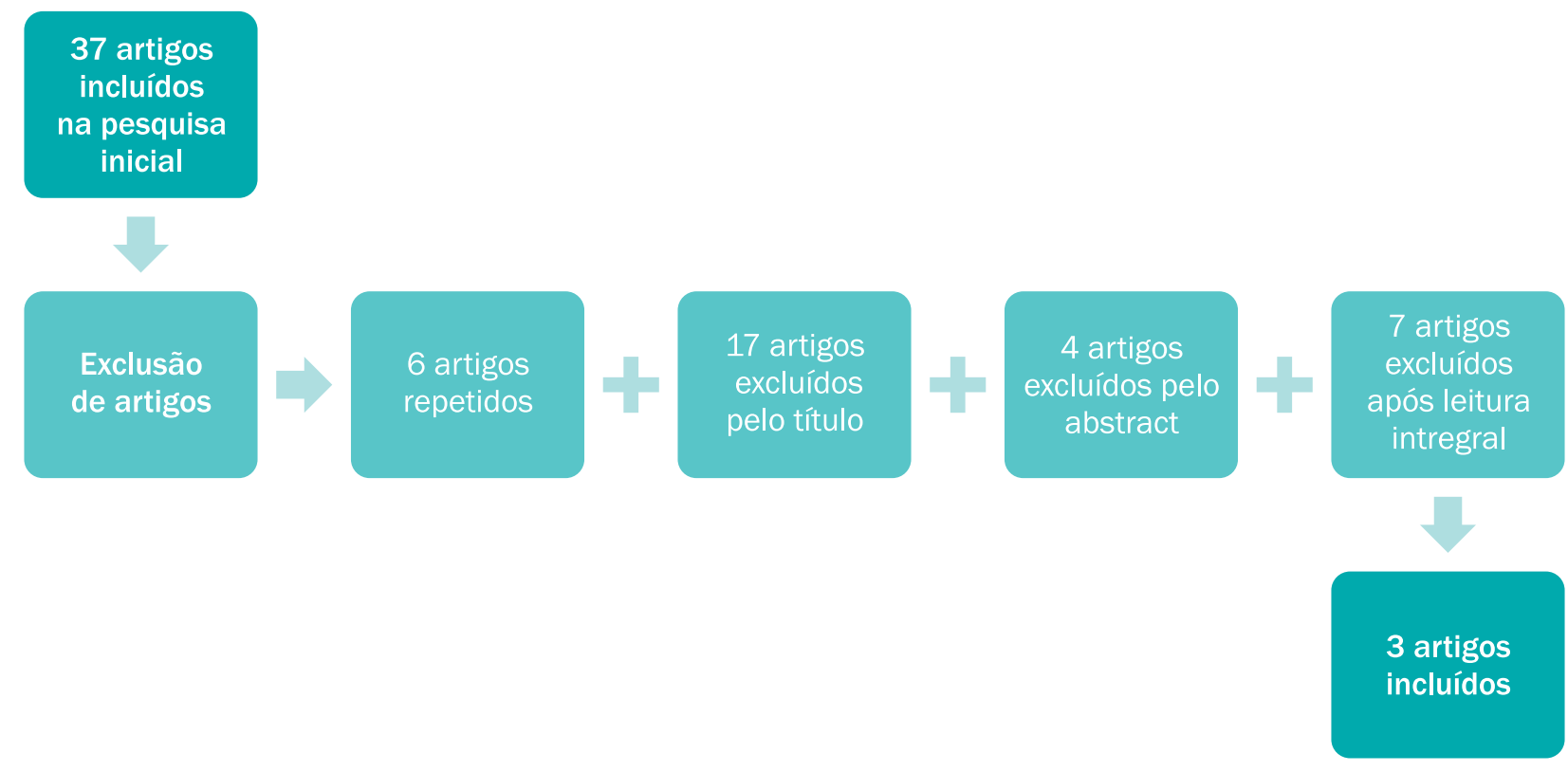

Critérios de exclusão:

- Artigos duplicados

- Ensaios clínicos incluídos em revisões sistemáticas

- Discordância com o objetivo da revisão

- População previamente intervencionada 
Tabela 1. Artigos incluídos na Revisão Baseada na Evidência

\begin{tabular}{|c|c|c|c|c|c|}
\hline REFERÊNCIA & AMOSTRA & INTERVENÇÃO & OUTCOMES & RESULTADOS & NE \\
\hline $\begin{array}{l}\text { ECAC } \\
\text { Hui A.C. et al. }{ }^{3} \\
2011\end{array}$ & $\begin{array}{l}\text { Adultos }(n=140) \text { com } \\
\text { diagnóstico de STC } \\
\text { com base clínica e } \\
\text { confirmada por EMG }\end{array}$ & $\begin{array}{l}\text { Grupo } 1 \text { - } \\
\text { gabapentina } 300 \mathrm{mg} \\
\text { id } 1 \text { semana } \rightarrow \text { bid } \\
1 \text { semana } \rightarrow \text { tid até } \\
\text { completar } 8 \text { semanas } \\
\text { Grupo } 2 \text { - placebo }\end{array}$ & $\begin{array}{l}\text { - Avaliar a melhoria } \\
\text { sintomática global } \\
\text { (GSS) às } 0,2 \mathrm{e} \\
8 \text { semanas de } \\
\text { tratamento }\end{array}$ & $\begin{array}{l}\text { - A gabapentina não produz uma } \\
\text { redução significativa na severidade } \\
\text { dos sintomas quando comparada } \\
\text { com o placebo ao longo de um } \\
\text { período de oito semanas }\end{array}$ & 1 \\
\hline $\begin{array}{l}\text { ECAC } \\
\text { Eftekharsadat } \\
\text { B. et al. }{ }^{4} \\
2015\end{array}$ & $\begin{array}{l}\text { Adultos ( } \mathrm{n}=90 \text { ) com } \\
\text { diagnóstico de STC } \\
\text { baseado nos critérios } \\
\text { de diagnóstico da } \\
\text { Academia Americana } \\
\text { de Neurologia }\end{array}$ & $\begin{array}{l}\text { Grupo A - } \\
\text { gabapentina } 100 \mathrm{mg} / \\
\text { dia } \\
\text { Grupo B - } \\
\text { gabapentina } 300 \mathrm{mg} / \\
\text { dia } \\
\text { Grupo C - placebo }\end{array}$ & $\begin{array}{l}\text { - Avaliar a } \\
\text { melhoria da dor } \\
\text { (VAS), melhoria } \\
\text { sintomática (SSS) } \\
\text { e funcional (FSS) } \\
\text { e a eficácia do } \\
\text { tratamento (BCTQ) } \\
\text { - Avaliar a melhoria } \\
\text { na electromiografia } \\
\text { (CMAP e SNAP) }\end{array}$ & $\begin{array}{l}\text { - Grupos A e B, em comparação } \\
\text { com o grupo C, apresentam } \\
\text { valores de VAS, SSS, FSS e BCTQ } \\
\text { significativamente menores } \\
\text { ( } p<0,05) \text {. } \\
\text { - Em todos os grupos houve melhoria } \\
\text { significativa no VAS, força de } \\
\text { pinça, SSS, FSS e score BCTQ pós } \\
\text { tratamento, exceto no CMAP e SNAP. } \\
\text { - Comparando o grupo A com o B, } \\
\text { houve melhoria significativa na } \\
\text { força de pinça e no score SSS no } \\
\text { grupo B ( } p<0,05 \text { ), mas as diferenças } \\
\text { entre os grupos noutras variáveis } \\
\text { não foram significativas. }\end{array}$ & 1 \\
\hline $\begin{array}{l}\text { Coorte } \\
\text { prospectivo } \\
\text { Taverner D. } \\
\text { et al. } .^{5} \\
2008\end{array}$ & $\begin{array}{l}\text { Adultos }(n=25) \text { com } \\
\text { STC diagnosticado por } \\
\text { EMG }\end{array}$ & $\begin{array}{l}\text { Gabapentina } 300 \mathrm{mg} \\
8-8 \mathrm{~h} \text {, com aumento } \\
\text { semanal da dose } \\
\text { até ao máximo de } \\
1,800 \mathrm{mg} / \text { dia, ao } \\
\text { longo de } 6 \text { meses }\end{array}$ & $\begin{array}{l}\text { - Avaliar a eficácia } \\
\text { analgésica e a } \\
\text { segurança da } \\
\text { gabapentina no } \\
\text { tratamento da STC } \\
\text { - Avaliar a evolução } \\
\text { do EMG aos } \\
6 \text { meses de } \\
\text { tratamento }\end{array}$ & $\begin{array}{l}\text { - Redução estatisticamente } \\
\text { significativa da dor ( } p=0,001 \text { ) e da } \\
\text { pontuação na escala da intensidade } \\
\text { dos sintomas ( } p=0,008 \text { ), sem } \\
\text { alteração evidente na capacidade } \\
\text { funcional. } \\
\text { - Relativamente ao EMG basal, o } \\
\text { atingimento neuropático manteve- } \\
\text { se estável em } 52,6 \% \text {, melhorou } \\
\text { em } 5,3 €, \text { progrediu em } 15,8 \% \text { e } \\
\text { regrediu em } 26,3 \% \text {. }\end{array}$ & 2 \\
\hline
\end{tabular}


No ECAC de Hui A.C. et al. ${ }^{9}, 140$ adultos com diagnóstico clínico de STC e confirmado por eletromiografia (EMG), foram aleatoriamente distribuídos por dois grupos: no grupo 1 foi administrada gabapentina 300mg uma vez por dia, com aumento subsequente até três vezes por dia, durante 8 semanas, e no grupo 2 foi dado placebo. Na avaliação da melhoria sintomática global (GSS), às 0,2 e 8 semanas de tratamento, a gabapentina não produziu uma redução significativa na severidade dos sintomas quando comparada com o placebo.

Trata-se de um estudo de elevada qualidade, com dupla-ocultação e com um follow-up, pelo que se atribui um Nivel de Evidência 1.

Num outro ECAC, realizado por Eftekharsadat B. et al. ${ }^{10}$, cuja população era constituída por 90 adultos com diagnóstico de STC baseado nos critérios de diagnóstico da Academia Americana de Neurologia, a intervenção foi realizada em 3 grupos, onde variava a dose de gabapentina administrada durante dois meses (A - 100mg/ dia, B - 300mg/dia, C - placebo). Os Grupos A e B, em comparação com o grupo $\mathrm{C}$, apresentaram valores significativamente menores $(p<0,05)$ na Escala Visual Analógica (VAS), na Escala de Severidade de Sintomas (SSS), na Escala do Estado Funcional (FSS) e no Questionário de Boston (BCTQ). Após tratamento, não se verificou em nenhum grupo alterações significativas na EMG, quer a nível do componente motor quer do sensorial do potencial de ação (CMAP e SNAP, respetivamente). Comparando o grupo A e $B$, houve melhoria significativa na força de pinça e do score SSS no grupo $B(p<0,05)$, mas as diferenças entre os grupos noutras variáveis não foram significativas. 0 presente estudo concluiu que a gabapentina era útil no tratamento dos sintomas da STC, nomeadamente na dose de $300 \mathrm{mg} /$ dia.

Por se tratar de um ensaio clínico randomizado e controlado de alta qualidade, duplamente cego e com adequado follow-up, foi atribuído Nível de Evidência 1.

Em Taverner D. et al 11, um estudo de coorte prospetivo, cuja população era constituída por 25 adultos com STC diagnosticado por EMG e a intervenção era a administração de gabapentina 300mg de 8 em 8 horas, com aumento semanal da dose até à dose máxima de $1.800 \mathrm{mg} / \mathrm{dia}$, foi avaliada a eficácia analgésica e a segurança da gabapentina no tratamento da STC e avaliada a evolução do EMG aos 6 meses de tratamento.
Houve uma redução estatisticamente significativa da dor ( $p=0,001$ ) e uma redução significativa da pontuação na escala da intensidade dos sintomas ( $p=0,008)$, sem alteração evidente na capacidade funcional. Relativamente ao EMG basal, o atingimento neuropático manteve-se estável em 52,6\% dos casos, melhorou em 5,3\%, progrediu em $15,8 \%$ e em $26,3 \%$ a EMG foi normal.

As principais limitações deste estudo encontradas pelas autoras foram o baixo número de participantes $(n=25)$ e um follow-up de $76 \%$, pelo que se atribuiu um Nível de Evidência 2.

\section{Conclusões}

As autoras consideram que apesar de terem sido incluídos como evidência dois ensaios clínicos de alta qualidade e com Nível de Evidência 1, pelos achados inconsistentes entre os dois estudos e pela inclusão de uma coorte prospetiva com desenho de estudo com qualidade inferior, foi considerada não existir evidência da eficácia da gabapentina na melhoria sintomática da STC com força de recomendação $B$.

Apesar de em dois dos estudos se ter verificado alguma melhoria sintomática do STC, deve ser considerada a existência de algumas limitações, pois os estudos apresentam amostras com dimensões distintas, seguidas por curtos e diferentes intervalos de tempo (2 a 6 meses). 0 curto período de seguimento não permite antever efeitos a longo prazo ou a duração-alvo da utilização da gabapentina para obtenção dos efeitos pretendidos. Além disso, utilizaram-se diferentes posologias (100$1800 \mathrm{mg} / \mathrm{dia})$, sendo que nem todas apresentavam a mesma eficácia.

Desta forma, no futuro serão necessários novos estudos, multicêntricos, com amostras maiores e um período de seguimento mais longo, que clarifiquem: a eficácia da gabapentina, o esquema posológico, a duração-alvo da administração da gabapentina, os efeitos laterais exatos da gabapentina nas diferentes doses, a diferença do benefício da gabapentina usada isoladamente ou como complemento do tratamento cirúrgico, os benefícios a longo prazo e a população-alvo com maior benefício deste tratamentos (tendo em conta a idade, duração e intensidade/gravidade dos sintomas). 


\section{Referências Bibliográficas}

1. Padua L, Coraci D, Erra C, et al. Carpal tunnel syndrome: clinical features, diagnosis, and management. The Lancet Neurology 2016;15(12):1273-1284.

2. Verdugo R, Salinas R, Castillo J, Cea G. Surgical versus nonsurgical treatment for carpal tunnel syndrome. Cochrane Database of Systematic Reviews 2008.

3. Ren Y, Wang X, Wei Z, et al. Efficacy, safety, and cost of surgical versus nonsurgical treatment for carpal tunnel syndrome. Medicine 2016;95(40):e4857.

4. Shi Q, MacDermid J. Is surgical intervention more effective than non-surgical treatment for carpal tunnel syndrome? a systematic review. J Orthop Surg Res 2011;6(1):17.

5. Duman I, Aydemir K, Ozgul A, Kalyon T. Assessment of the Efficacy of Gabapentin in Carpal Tunnel Syndrome. J Clin Rheumatol 2008;14(3):175-177.

6. Erdemoglu A. The efficacy and safety of gabapentin in carpal tunnel patients: Open label trial. Neurol India 2009;57(3):300.

7. Moore R, Wiffen P, Derry S, Rice A. Gabapentin for chronic neuropathic pain and fibromyalgia in adults. Cochrane Database of Systematic Reviews. 2014.

8. Carneiro, A.V. "Como avaliar a investigação clínica. o exemplo da avaliação crítica de um ensaio clínico." GE- J Port Gastrenterol 2008; 15: 30-36

9. Hui AC, Wong SM, Leung HW, Man BL, Yu E, Wong LK. Gabapentin for the treatment of carpal tunnel syndrome: a randomized controlled trial. Eur.J Neurol 2011/5; 5: 726-730.

10. Eftekharsadata B, Babaei-Ghazanib A and Habibzadehc A. The Efficacy of 100 and $300 \mathrm{mg}$ Gabapentin in the Treatment of Carpal Tunnel Syndrome. Iran J Pharm Res 2015; 14 (4): 1275-1280.

11. Taverner D, Lisbona MP, Segalés N, et al. Eficacia de la gabapentina en el tratamiento del sindrome del tunel carpiano; Med Clin (Barc) 2008;130(10):371-3.

\section{Conflito de Interesses}

As autoras declaram não ter conflitos de interesses. 


\title{
Voluntariado no Panamá
}

\author{
Rita Ferreira*, Ana Portela**, Renata Almeida****
}

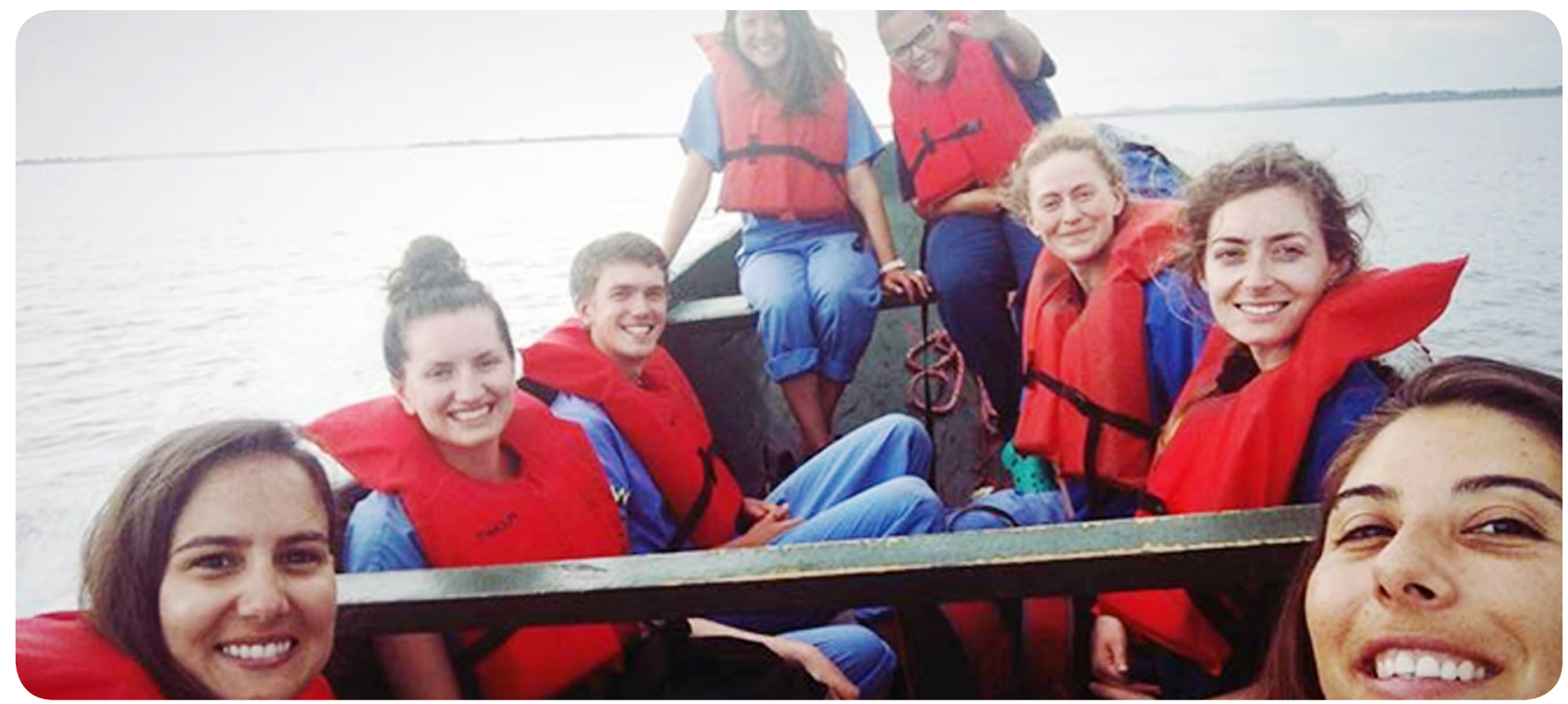

Foi no mês de Maio de 2018, que tivemos a nossa primeira experiência de voluntariado médico além-fronteiras. Como internas do $4^{\circ}$ ano de MGF, optámos realizar um estágio de voluntariado, durante duas semanas, no Panamá, mais precisamente em Bocas del Toro. Ambicionávamos uma experiência completamente distinta da nossa prática clínica diária onde, com poucos recursos, humanos e materiais, pudéssemos fazer a diferença.

Delineámos como objetivos para este estágio: conhecer a estrutura e organização do sistema de saúde do país escolhido através do acompanhamento e realização de consultas e visitas domiciliárias nas áreas da saúde materno-infantil, saúde de adultos e urgências; contactar com a realidade epidemiológica tão distinta da nossa; conhecer os fatores socioculturais que influenciam os cuidados de saúde e perceber quais os motivos mais frequentes de consulta/urgência e realizar atividades informativas na comunidade incentivando a profilaxia de doenças evitáveis.

Com base nestes objetivos, após pesquisa de diversas organizações de voluntariado, decidimos integrar a equipa dos Floating Doctors (FD), uma ONG que labora em
Bocas del Toro, e que tem como missão primordial reduzir a carga presente e futura de doenças no mundo em desenvolvimento e promover melhorias na prestação de cuidados de saúde em todo o mundo. Entre os seus objetivos estão a prestação de serviços de cuidados de saúde agudos e preventivos gratuitos; facilitar iniciativas de desenvolvimento da comunidade; reduzir a mortalidade infantil e materna e melhorar o acesso a cuidados médicos especializados em regiões em desenvolvimento.

Para além de vermos os nossos objetivos refletidos na missão dos FD, a forma como estes operam no Panamá despertou a nossa curiosidade: eles deslocam-se até às comunidades mais carenciadas e recônditas de Bocas del Toro, com difícil acesso a cuidados básicos de saúde, de barco! Bocas del Toro é, não só uma província panamenha, como um arquipélago, sendo composto por nove ilhas principais e mais de duas centenas de ilhotas.

Entrámos em contacto com a equipa dos FD e partimos rumo à aventura, com um misto de nervosismo e excitação na bagagem, rumo à ilha de San Cristóbal, onde se localiza a base dos FD, que foi a nossa casa durante as duas semanas. 


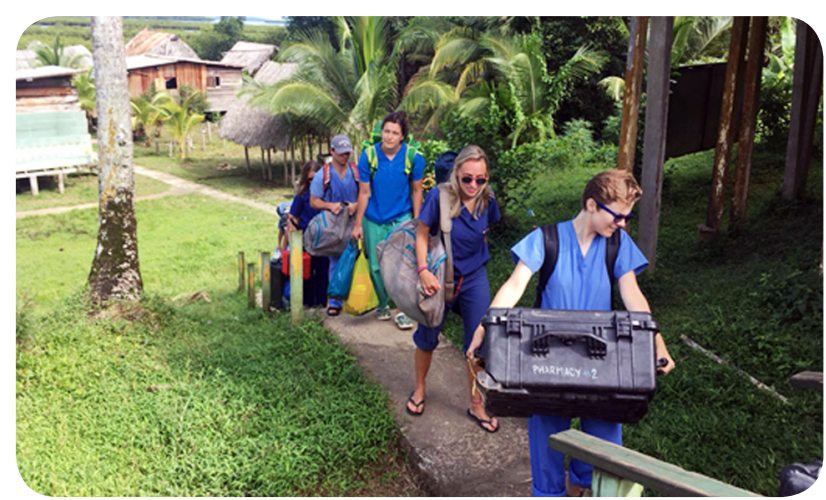

Todos os dias, exceto aos fins-de-semana, o sino da base soava às sete da manhã para o pequeno-almoço e, de seguida, para carregarmos o material médico para o barco onde nos deslocávamos para as povoações das ilhas vizinhas. Como diria o Dr. Ben, fundador dos FD, "If the patients cannot come to the clinic, our clinic must go to the patients." E era exatamente isso que fazíamos. Quando chegávamos às povoações, que já sabiam previamente da nossa chegada, após descarregarmos todo o material do barco, "montávamos" a clínica num espaço amplo com mesas e cadeiras existentes nos locais. Organizávamos nos em três zonas de atuação com base na experiência de cada elemento (uma vez que integravam a equipa: enfermeiros, estudantes de medicina, internos de formação médica; médicos especialistas): a zona de receção dos utentes (equivalente ao nosso secretariado); o intake (equivalente à triagem onde eram avaliados os vitais e registadas as queixas dos pacientes); por fim, o grupo dos providers, dividido em equipas de três elementos, do qual fazíamos parte, que era onde se desenrolava a consulta propriamente dita e onde tínhamos acesso aos fármacos. Fazíamos as consultas em espanhol e falávamos com a maioria dos colegas em inglês, o que era desafiante e exigia um esforço adicional.

A medicina praticada era preventiva e curativa, tal como no nosso dia-a-dia em Portugal, com a diferença abismal do tipo de pacientes que tratávamos, tanto a nível cultural/crenças, como de patologias, assim como de bens materiais de que dispúnhamos.

A maioria dos pacientes que observamos eram mulheres em idade fértil e crianças. As populações eram visitadas de três em três meses assegurando uma vigilância continuada de diabéticos, hipertensos, grávidas e mulheres em idade fértil.

Apesar da oferta da contraceção - preservativo e administração de Depo-Provera intramuscular, a taxa de natalidade era elevada, e muitas crianças até aos dois anos morriam (sobretudo devido às precárias condições sanitárias), motivo pelo qual a grande maioria até

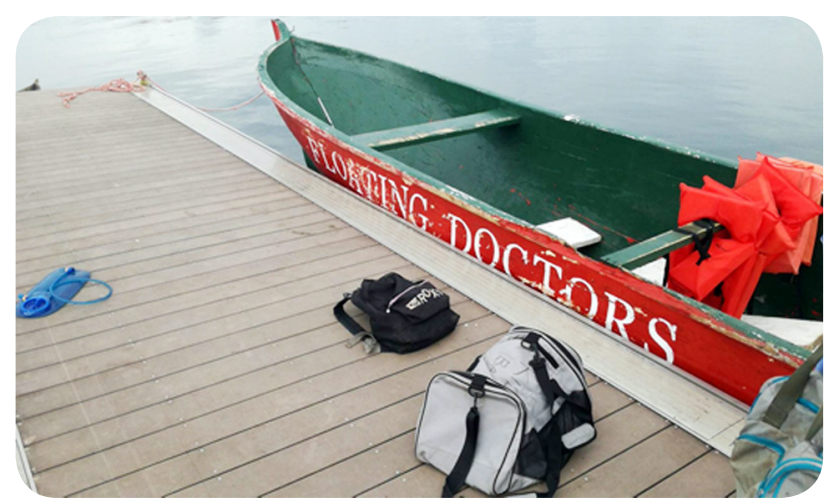

esta idade se chamava "chichi" e só depois Ihes era dado o nome definitivo. Fato este, que despertou em nós inquietude e tristeza. A maioria das patologias agudas que observámos eram do foro infecioso: escabiose, pediculoses, parasitoses gastrointestinais, infeções respiratórias e da pele. Oportunisticamente, promovemos a educação para a saúde entregando, inclusivamente, material de higiene pessoal como sabonetes, escovas e pastas dos dentes e relembrar o seu uso.

Após tarefa cumprida, carregávamos novamente o material e regressávamos à base onde todos os voluntários jantavam numa sala comum, partilhavam as experiências do dia e se conheciam melhor. Havia ainda um momento semanal para arrumação da farmácia da base, onde se contabilizavam os fármacos utilizados e se reabasteciam as malas, assim como para discussão de casos clínicos. A sexta-feira era o dia de reavaliar os casos que tínhamos deixado agendados ao longo da semana, nas diferentes povoações visitadas.

A estadia na base, apesar de rodeada por quilómetros de mar e vegetação, era agradável pela calmia e natureza envolvente. Dormíamos em beliches e o banho era de água fria, mas tolerável tendo em conta a temperatura exterior. lamos preparadas para dormir no chão, em sacos-cama, mas tal não se verificou porque não tivemos a oportunidade de experienciar os multiday clinic em que os FD se deslocam durante uma semana apenas para uma povoação, o que acontecia com as mais numerosas e distantes.

O balanço final desta experiência foi largamente positivo. Podemos afirmar que os objetivos a que nos propusemos foram atingidos e que esta experiência foi única, tocante e, sem duvida, inesquecível. Ficámos com vontade de repetir a experiência e aconselhamos a quem o pondera fazer, não hesitar.

\section{Conflito de Interesses}

As autoras declaram não ter conflitos de interesses. 



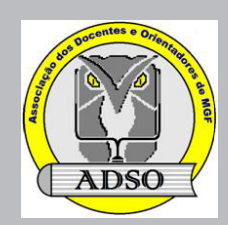

Associação dos Docentes e Orientadores de Medicina Geral e Familiar Revista Semestral I Número 08 I setembro de 2018 